Journal of Applied Fluid Mechanics, Vol. 2, No. 1, pp. 55-69, 2009.

Available online at www.jafmonline.net, ISSN 1735-3572, EISSN 1735-3645.

DOI: $10.36884 / \mathrm{jafm} .2 .01 .11857$

\title{
Transient Thermal Behavior of a Vertical Solar Storage Tank with a Mantle Heat Exchanger During No-Flow Operation
}

\author{
A. Barzegar ${ }^{1}$ and A. A. Dehghan ${ }^{2}$ \\ ${ }^{1,2}$ School of Mechanical Engineering, Yazd University, Yazd, Iran \\ Email: adehghan@yazduni.ac.ir
}

(Received December 12, 2007; accepted October 29, 2008)

\begin{abstract}
Transient thermal behavior of a vertical storage tank of a domestic solar heating system with a mantle heat exchanger has been investigated numerically in the charging mode. It is assumed that the tank is initially filled with uniform cold water. At an instant of time, the hot fluid from collector outlet is uniformly injected in the upper section of the mantle heat exchanger and after heat transfer with the fluid inside the tank, withdrawn from the bottom part of the heat exchanger. The conservation equations in the cylindrical coordinate and in axis-symmetric condition have been used according to the geometry under investigation. Governing equations have been discretized by employing the finite volume method and the SIMPLER algorithm has been used for coupling between momentum and pressure equations. The Low Reynolds Number (LRN) $k-\omega$ model is utilized for treating turbulence in the fluid. First, the transient thermal behavior of heat storage tank and the process of formation of thermal stratification in the heat storage tank were investigated. Then, the influence of Rayleigh number in the heat storage tank, Reynolds number in the mantle heat exchanger and vertical positioning of mantle on the flow and thermal fields and the formation of the thermal stratification was investigated. It is found that for higher values of Rayleigh number, a more suitable thermal stratification is established inside the tank. Also it is noticed that increasing the incoming fluid velocity through the mantle heat exchanger causes a faster formation of the thermal stratification. A superior thermal performance was achieved when the mantle heat exchanger is positioned at the middle height of the storage tank.
\end{abstract}

Keywords: solar storage tank, thermal stratification, mantle heat exchanger

\section{NOMENCLATURE}

\begin{tabular}{|c|c|}
\hline Gr & Grashof number $G r=\frac{g \beta\left(T_{\text {hot }}^{\prime}-T_{\text {cold }}^{\prime}\right) H^{3}}{v^{2}}$ \\
\hline $\mathrm{H}$ & $\begin{array}{l}\text { height of the storage tank (characteristic } \\
\text { dimension) }\end{array}$ \\
\hline$k$ & turbulent kinetic energy \\
\hline $\mathrm{R}$ & radius of the storage tank \\
\hline $\mathrm{r}$ & radial variable \\
\hline$R a$ & Rayleigh number $R a=G r \times \operatorname{Pr}=\frac{g \beta\left(T_{\text {hot }}^{\prime}-T_{\text {cold }}^{\prime}\right) H^{3}}{v \alpha}$ \\
\hline $\mathrm{Re}$ & Reynolds number $\operatorname{Re}=\frac{u_{r e f} H}{v}$ \\
\hline $\mathrm{T}$ & local temperature \\
\hline $\mathrm{t}$ & physical time \\
\hline$u_{r}, u_{z}$ & $\begin{array}{l}\text { radial and axial velocity components, } \\
\text { respectively }\end{array}$ \\
\hline
\end{tabular}

$\begin{array}{ll}u_{\text {in }} & \text { inlet fluid velocity to mantle annular } \\ \mathrm{z} & \text { axial variable }\end{array}$

Greek letters

$\alpha$ thermal diffusivity

$\beta$ volumetric expansion coefficient

$v$ kinematic molecular viscosity

$v_{t}$ kinematic turbulent viscosity

$\omega$ specific dissipation rate of $k$

Superscripts

' dimensional quantity 


\section{INTRODUCTION}

Harnessing solar energy is one of the interesting fields for applying the resources of renewable energy. Because of transient nature of solar irradiation, different designs and methods are being used in solar heating systems in order to store solar energy. The most current systems for storing solar energy use water as a storage media. This is due to the fact that water is being available, low in cost and non-toxic as well as having high thermal capacity. Solar domestic heating water systems are among systems used for absorbing solar energy during day time and using it on demand. A solar domestic heating water system consists of solar collector, thermal reservoir, auxiliary heater, heat exchanger, and a series of junction tubes which connect solar collector into the storage tank. It also includes city water inlet and hot water outlet. The water inside the storage tank is heated through liquid circulation in the collector cycle. Collector cycle is designed as open or closed circuits. In open-circuit cycle, fluid inside the collector is directly injected into the water inside the tank. In the case of closed circuit cycle, in order to transform heat between collector and water inside the tank, heat exchanger is used. In closedcircuit systems heat exchanger is designed in different ways. These exchangers include a series of tubes or spirals that are floating or placed inside the storage tank or as a series of tubes wrapped around the storage tank, or as circular shell surrounding the peripheral of the tank. The most common kind of heat exchanger used in solar water heaters is mantle heat exchangers. In these systems collector outlet is connected between the middle and upper part of the heat exchanger. The usable hot water is extracted from the upper part of the tank and is replaced by cold water (provided from city water). In thermosyphon systems, the flow rate in the collector loop is normally low (around 0.6 liter $/ \mathrm{min}$.) and depends on the solar irradiation and flow restrictions in the collector loop while the flow rate is higher in the consumption loop and depends on the amount of hot water consumption (Alizadeh, 1999). Of considerable problems in increasing the efficiency of solar water heater system is to use tanks with thermal stratification. In a naturally stratified thermal storage tank, buoyancy forces created by temperature dependent density differences maintain the separation between warm and cool volume of liquid across a thin thermal transition region. This region with a steep temperature gradient is known as the thermocline zone. Thermocline thickness is commonly used as an indication of thermal stratification in a thermal storage tank. In a well designed stratified storage tank, the thermocline zone should be narrow and the erosion in the thermocline results in the degradation of thermal stratification. Stratified tank is the most attractive choice in low-to-medium temperature thermal storage applications due to its simplicity and low cast.

Factors influencing in the thermal stratification degradation in solar energy storage tanks are forced convection flow through the tank, heat loss to the surrounding environment, thermal mixing at the inlet, natural convection flow induced by conduction within the tank walls and heat diffusion inside the tank due to the vertical temperature gradient within the tank (Zurigat, 1989; Shyu et al., 1989). In order to study the effect of different parameters on thermal stratification in storage tanks, research has been conducted experimentally and numerically. The study of thermal behavior of storage tanks includes dynamic and static modes. In the static mode, there is no flow in or out of the storage tank while in the dynamic mode of operation, the consumption loop is active and the inflow to or outflow from the tank is considered. Lavan and Thompson (1977) performed an experimental study on a thermally stratified, vertical hot water storage tank. Experimental measurements were made on various height/diameter ratios, inlet port location and geometry, inlet-outlet temperature difference and different mass-flow rate. Their study showed that better thermal stratification can be obtained by increasing the ratio of the tank height to its diameter, increasing the diameter of the inlet port, and or increasing the difference between the inlet and outlet water temperature. Cole and Bellinger (1982) concluded that maximum thermal stratification can be achieved inside the storage tank with a height to diameter ratio of four. The studies of Ismail et al. (1997) and Hahne and Chen (1998) confirmed Cole and Bllinger (1982) conclusion while Nelson et al. (1997) suggested aspect ratio of three for the best thermal stratification. The earliest research about the effect of the tank wall conductivity on decreasing the thermal stratification was conducted by Miller (1977). He showed that due to low thermal conductivity of water, diffusion across the thermocline is a secondary factor in degrading thermal stratification, whereas fluid mixing during early stages of charging and discharging, thermal loss with surrounding environment and thermal conductance through the tank walls are among the more primary factors affecting thermal destratification. It is clear that in static mode or no-flow condition, the degradation of thermocline zone is severely affected by thermal conductance of the tank wall. In a tank with higher thermal conductive walls, thermocline zone is diminished more rapidly. Hence, in the static mode, thermal conductance of wall has a pronounced effect on the degradation of thermal stratification. In this case, it is recommended to use a layer of insulator covering the interior surface of the tank wall. Lightstone et al. (1989) showed that in the dynamic mode, the effect of wall thermal conductance on the thermal stratification degradation is negligible. Mixing flow in the inlet opening is considered as one of the most important parameters in the degradation of thermal stratification. Therefore, in order to reduce the inlet mixing, different inlet configurations were considered and studied. The form of the inlet diffusers and their influences on the mixing level inside a cold water storage tank was the subject of Wildin and Truman (1985) and Wildin (1996) studies. Zurigat et al. (1988) investigated the effect of different inlet flow designs on the thermal stratification inside a system employing a combination of fresh and salty water. Advantages of this configuration are the elimination of wall conductance and thermal loss to the environment effects on the degradation of thermal stratification. Therefore, in this case, the only factor which affects the degradation of stratification is mixing fluid around the inlet port. Shariah et al. (1996) studied the thermal performance of a vertical domestic solar water heating system operating with natural circulation 
(thermosyphon) by employing TRANSYS simulation program. They investigated the effect of tank height on the annual solar fraction of the system for different hot water load temperatures and storage tank volumes and the response of the system to the ratio of the storage tank volume to the collector area. Heat exchanger was not considered in the TRANSYS software version used by Shariah et lof (1996). Their model can only be used to simulate direct systems, while in most common solar storage tanks heat exchanger is one of the component of the collector loop. Later, Morrison et al. (1999) developed a more sophisticated model of TRANSYS software that modeled an indirect solar domestic hot water system with horizontal storage and a mantle heat exchanger. Nevertheless this model describes systems in which the hot fluid inlet is placed at the bottom of the annulus of the mantle heat exchanger, contrary to the common systems used in solar domestic storage systems where hot water from collector is fed to the upper part of the mantle heat exchanger. Therefore, Andres et lopez (2002) suggested a new TRNSYS model for solar domestic water heater with a horizontal storage tank with a mantle heat exchanger having its inlet hot water at the top of the annular gap. Eames and Norton (1998) studied the effect of hot water inflow position on the development of the thermal stratification in both vertical and horizontal energy storage tanks which are pre loaded with uniform cold water in the dynamic mode of operation for low inflow Reynolds numbers. The results of their studies showed that better thermal stratification is developed in the vertical tanks than the horizontal tanks with the same dimensions. It is observed that thermocline zone in the vertical tank has a steeper gradient than the horizontal tanks which is an indication of a more favorable thermal stratification.

In a numerical and experimental study, Oliveski et al. (2003) obtained temperature and velocity fields inside a vertical hot water storage tank during a cool-down process. In the first stage of their study, they compared the experimentally obtained temperature distribution along the vertical direction with the numerical simulation. In the second stage, they numerically studied the influences of the tank aspect ratio, its volume and outer insulation thickness on the transient thermal behavior of the storage tank.

Dehghan et al. (2005) experimentally investigated thermal performance of a vertical solar hot water tank employed in a domestic solar water heating system. They used a domestic solar heating water system which is installed on a roof top of a four person family house. The thermal characteristics of the system is evaluated by hourly measuring the temperature distribution inside the tank, solar collector flow rate, and its inlet and outlet temperatures as well as the load/consumption flow rates under the realistic operating conditions. The study conducted over 120 days, mostly during the summer time and it was observed that the thermal stratification is well established from $11 \mathrm{am}$ till $10 \mathrm{pm}$ especially during August to September, enabling the tank to provide the necessary amount of hot water for the occupants.

From the review of the previously published literatures, it was observed that the study of solar water heater tanks equipped with mantle or shell type heat exchangers has received negligible attention and the fluid inside solar collector loop has been directly injected into thermal storage tank. However, most of the practical solar water storage tanks employ mantle type heat exchanger in the collector loop to provide thermal communication between the collector loop and the storage tank. Therefore, in the present study, thermal behavior of a cylindrical vertical tank employed in a solar domestic heating water system with a mantle heat exchanger is modeled numerically. In the first part of this investigation, the transient behavior of the storage tank and its mantle during static operation or no-flow condition is studied. During the static mode of operation, the solar collector feeds the mantle with hot water and the water inside the tank progressively warms up while there is no cold water supply to or hot water removal from the tank. The transient performance of the same tank under the dynamic mode with inflow through and outflow from the storage tank was also investigated (Barzegar, 2007). However results are not presented here due to the space limitation.

\section{Physical Problem}

The physical shape of the thermal storage tank under consideration is a vertical cylinder with mantle heat exchanger acting as a hot water jacket which surrounds part of the tank lateral surface .A schematic cut view of the modeled thermal storage tank is illustrated in Fig. 1. According to the figure, fluid outlet from collector is uniformly injected in the upper section of heat exchanger and after heat exchange with the fluid inside the tank; it is withdrawn from the bottom part of the heat exchanger. It is assumed that the collector hot water is uniformly charged over the top surface of the mantle heat exchanger by means of a flow distributor and also it is uniformly extracted through the bottom outlet. Therefore, it is assumed that the flow and thermal fields are two dimensional and axis-symmetric. The velocity of inlet flow to the mantle heat exchanger is calculated according to the inlet hot water flow rate and the cross sectional area of the heat exchanger. The radius of the vertical thermal storage tank is equal to $0.25 \mathrm{H}$. Gap width in the mantle heat exchanger is assumed to be $0.02 \mathrm{H}$.

In Fig. 1, the mantle heat exchanger is positioned in the middle height of the storage tank although its position is varied in this study and its effects on the flow and thermal fields is investigated and discussed.

\section{GOVERNING EQUATIONS AND NUMERIC}

\subsection{Governing equations}

The governing equations include continuity, momentum and energy equations in the cylindrical co-ordinate as well as two additional equations for turbulence modeling. Natural convection flow is considered for the fluid inside the tank and since the hot fluid is directly entered into the mantle heat exchanger with low gap width, forced convection flow is assumed to be dominant inside the mantle heat exchanger. The height of the storage tank is taken to be the reference length and the following dimensionless variables are introduced accordingly. 
$r=\frac{r^{\prime}}{H} \quad, \quad z=\frac{z^{\prime}}{H} \quad, \quad u_{r}=\frac{u_{r}^{\prime}}{u_{r e f}} \quad, \quad u_{z}=\frac{u_{z}^{\prime}}{u_{r e f}} \quad, \quad \frac{\partial T}{\partial r}=\frac{\partial u_{z}}{\partial r}=u_{r}=0$

$T=\frac{T^{\prime}-T_{\text {cold }}^{\prime}}{T_{\text {hot }}^{\prime}-T_{\text {cold }}^{\prime}}, t=\frac{t^{\prime} u_{\text {ref }}}{H}, k=\frac{k^{\prime}}{u_{\text {ref }}^{2}}, \omega=\frac{\omega^{\prime} H}{u_{r e f}}$

For natural convection in the tank, $\sqrt{\beta g\left(T_{\text {hot }}^{\prime}-T_{\text {cold }}^{\prime}\right) H}$ is used as the reference velocity and for forced convection in annular mantle, the inlet velocity is considered to be the reference velocity. In the non-dimentionalized variables, $T_{\text {hot }}^{\prime}$ and $T_{\text {cold }}^{\prime}$ are inlet mantle hot fluid temperature and initial cold fluid temperature in the storage tank respectively.

The fluid in the tank and heat exchanger is viscous, incompressible and Newtonian. The thermo-physical properties of the fluid are assumed to be constant except the density variation with temperature for which the Boussinesq approximation is used. The governing equation may be cast into a general form appropriate for the control volume formulation as follows (Patankar, 1980).

$$
\frac{\partial \phi}{\partial t}+\operatorname{div}(u \phi)=\operatorname{div}\left(\Gamma_{\phi} \operatorname{grad} \phi\right)+S_{\phi}
$$

The governing equations in the non-dimensional forms along with the definition of their respective coefficients and source terms are all summarized in Table 1.

\subsection{Boundary conditions}

The velocity boundary conditions on the top and lateral surfaces of the tank and also on the lateral surface of the heat exchanger are expressed as follows.

$u_{r}=u_{z}=0$

The temperature boundary condition on the lateral surface of the tank and mantle is as follows.

$\frac{\partial T}{\partial r}=0 \quad$ (Except at the tank and mantle interface)

The horizontal top and bottom surfaces of the tank are assumed to be adiabatic and hence the following temperature boundary condition is applied.

$\frac{\partial T}{\partial z}=0$

At the mantle inlet, the following boundary conditions are employed.

$u_{r}=0, u_{z}=-1, T=1$

At the mantle outlet, the following Neumann boundary conditions are utilized. However, the mantle outlet velocity is corrected by utilizing the mass imbalance between the inlet and outlet ports (Versteeg, Malalasekera, 1995).

$$
\frac{\partial T}{\partial z}=\frac{\partial u_{r}}{\partial z}=\frac{\partial u_{z}}{\partial z}=0
$$

Along the symmetry axis of the tank, the following boundary conditions are applied.
It is assumed that the tank has negligible thickness and therefore at the interface of the mantle heat exchanger and the tank, the continuity of temperature and heat flux must be satisfied. Therefore by applying the following nondimensional boundary condition at the tank and the mantle interface, the interface temperature at each time step is updated by utilizing the neighboring nodal temperatures inside the tank and the mantle region at the previous time level.

$$
\left(\frac{\partial T}{\partial r}\right)_{\text {mantle side }}=\left(\frac{\partial T}{\partial r}\right)_{\text {tank side }}
$$

The governing equations have been discretized by employing the finite volume method and solutions are obtained by utilizing transient SIMPELER algorithm (Patankar, 1980). Referring to the governing equations (Table 1), it may be seen that there is no explicit equation for pressure field. The SIMPLER (SIMPLE Revised) algorithm of Patankar (1980) which is an improved version of SIMPLE, is a mean to generate a discretized equation for pressure from the discretized continuity equation. Thus the intermediate pressure field is directly obtained without utilizing pressure correction equation while in the SIMPLE algorithm, pressure field is obtained by means of pressure correction equation. As in the SIMPLER algorithm the pressure field is obtained directly by solving the discretized pressure equation, the convergence to the final results is believed to be faster.

The flow is considered to be laminar up to the Rayleigh numbers of around $R a=1 . \times 10^{7}$ and for higher Rayleigh number values, turbulence parameters are involved. The Wilcox LRN k- $\omega$ model has been used for turbulence modeling (Wilcox, 1993). The production, dissipation and source terms as well as the constants and damping functions employed in this model are all summarized in Table 1. The Reynolds number in the mantle heat exchanger is defined on the basis of the fluid inlet velocity into the mantle and mantle gap width. Therefore, the value of Reynolds number in the heat exchanger is also considered to be one of the variable parameters.

\section{RESUlts AND Discussions}

Investigating the evolution of the thermal and flow fields during the charging mode of operation and the process of formation of thermal stratification inside the storage tank for various governing parameters is the main objective of the present study. The difference between the hot fluid temperature entered into the heat exchanger and the initial temperature of cold fluid stored in the tank which is reflected as the Rayleigh number, the mantle hot water flow rate which is represented by the Reynolds number, and the vertical positioning of the mantle are among the variable parameters which are investigated and their influences on the flow and thermal fields are investigated and discussed. 
In order to validate the computer program and the solution procedure, the problem of natural convection in vertical cylinder under uniform heat flux boundary conditions as shown in Fig. 2, is solved numerically and the obtained results are compared with the results obtained by Lemember and Petit (1998). In Figs. 3 and 4, the comparison between our results and Lemember and Petit (1998) study are presented. Close agreements between the two results are observed.

For turbulent natural convection, due to the lack of benchmark experimental or numerical results for cylindrical enclosures, the turbulence model used in the present study were validated against the experimental data obtained by Cheeswright et al. (1986) and the numerical simulation of Peng and Davidson (1999) in the form of velocity and temperature profiles as well as the turbulence kinetic energy distribution. Papanicolaou and Belessiotis (2002) also utilized the same procedure for validating their numerical simulation of natural convection within a cylindrical geometry. Very close agreement between them are observed, confirming the numerical procedure in our study. The details of the above comparison are not presented here for the sake of brevity and are presented elsewhere (Barzegar, 2007).

Non uniform mesh distribution in both $\mathrm{r}$ and $\mathrm{z}$ directions is employed by utilizing a hyperbolic mesh generating function. Compact grids are used along the solid walls in order to capture the possible steep gradients at the vicinity of the walls. For higher values of Rayleigh number, the mesh density along the solid walls is further increased. It is found that mesh size of $140_{z} \times 90_{r}$ is adequate for the present study. The variation of Nusselt number along the tank and the mantle interface which is an indication of the rate of heat transfer from the mantle hot fluid stream to the storage tank is shown in Fig. 5 for different mesh sizes.

\subsection{Transient thermal behavior of the heat storage tank}

For investigating the transient thermal behavior of the solar storage tank under consideration, it is assumed that the tank is initially filled with uniform cold water with a nondimensional temperature of $T=0$. At $t \geq 0$, the mantle heat exchanger is charged with a hot fluid, having a nondimensional temperature of $T=1$. As time elapses, a natural convection flow field is formed inside the storage tank due to the heat transfer from the mantle hot stream fluid to the initially cold fluid inside the tank.

In Fig. 6, the evolution of the flow and thermal fields in the form of isotherms and streamlines are plotted for $R a=1 . \times 10^{7}$ and for various values of dimensionless times $t=20, t=50, t=100, t=300$ and $t=500$. Due to the symmetry condition in respect to the vertical axis, isotherms are plotted in the right region of the tank while in the left symmetric portion, the streamlines are shown. The thermal field at the upper section of the mantle and its corresponding tank region is also magnified and shown for early stages of time as may be seen in the right of Figs. $6 a$ and 6 b.
As the hot fluid flow is initiated through the mantle heat exchanger, the tank cold fluid adjacent to the interface of the heat exchanger and the tank is progressively heated and flows upward due to the buoyancy force. The uprising warm fluid in the tank around the vicinity of the tank wall impinges to the top horizontal wall and turns towards the centerline of the tank and hence pushes the cold fluid to drop down around the centerline. Hence, a recirculation zone is formed at the top region of the tank as may be seen in Fig. 6a. As time elapses, the warm fluid at the top region is replaced with the warmer fluid, and pushes down the previously warm fluid layer, causing the formation of a stable thermal stratification as shown in Figs. 6d and 6e. The lower part of the tank is occupied with an almost stagnant cold fluid. The formation of the thermal stratification is more clearly shown in Fig. 7 in which the vertical temperature profiles along the central axis of the tank are plotted for various non-dimensional times. It is seen that as time goes on, the hot fluid having relatively uniform temperature fills the upper part of the tank and the lower region is occupied with the cold fluid. Between these two almost uniform hot and cold temperature regions, a zone with a temperature gradient is formed which is known as the thermocline region.

\subsection{The influence of the tank Rayleigh number}

In this section the influence of the Rayleigh number on the thermal and flow fields is considered by varying the Rayleigh number from $R a=1 . \times 10^{6}$ to $R a=1 . \times 10^{10}$.In Fig. 8, the streamlines and isotherms inside the tank are plotted for various values of the Rayleigh number at the same normalized time of $t=100$. In order to evaluate the flow fields at the same elapsed time, the non-dimensional times are normalized in respect to the reference velocity for the Rayleigh number $R a=1 . \times 10^{6}$. It is seen that as $R a$ is increased, a stronger buoyant uprising warm flow adjacent to the vertical wall is formed as indicated by the compactness of the streamlines along lateral vertical wall of the tank. The center of the recirculation moves towards the upper horizontal top wall. It is also seen that velocity and thermal boundary layers adjacent to the lateral vertical wall of the tank are formed and their thicknesses become thinner as $R a$ is increased. A weak secondary shear recirculation is also formed at the bottom region which is due to the stronger down-coming cold fluid for higher values of $R a$ number. Close look at the isotherms indicates that at a same elapsed time, a more stable and favorable thermal stratification is formed as $R a$ is increased. At the higher values of the Rayleigh number, the upper region of the tank is soon filled with an almost uniform hot fluid and the bottom region is occupied with the cold fluid and there is a strong temperature gradient in the middle region of the tank.

\subsection{The influence of the mantle location}

Obtaining an appropriate thermal stratification inside the tank with a proper amount of high quality hot water in the upper region of the tank is certainly depending on the peripheral mantle location. 
In order to study the influence of the mantle heat exchanger location, the mantle is placed in three different statuses, i.e., in the bottom, middle and top positions around the tank as shown in Fig. 9. For every case, it is assumed again that the hot fluid is charged from the top of the mantle and after delivering its thermal energy to the tank fluid, it is withdrawn from the bottom outlet.

In Fig. 10 the streamlines and isotherms are plotted for the Rayleigh number $R a=1 . \times 10^{8}$ and for dimensionless time of $t=1000$, corresponding to three different mantle positions which were shown in Fig. 9.

Comparing isotherms for three cases shown, it is concluded that placing the heat exchanger around upper position of the tank, the fluid on the upper part of the tank has a higher temperature at the same times and thermal stratification is formed over a higher section in the tank, while by placing heat exchanger around the bottom section of the tank, the maximum fluid temperature in the upper part of the tank is much lower than the two other cases and thermal stratification is created in much lower height of tank. It is seen from Fig. 10a, that a secondary recirculation zone is formed at the top of the tank which prevents the warm uprising fluid to reach the top of the tank and hence a temperature incursion is formed there. By placing the mantle in the middle or the top positions, the secondary recirculation is diminished and the center of the main circulation moves upward and becomes closer to the tank wall. For these two cases, the bottom region of the tank is occupied with a cold and relatively motionless fluid.

In Fig. 11, the vertical temperature profile is shown along the symmetry axis of the tank, for different dimensionless times and for three mantle locations. It is seen that for the bottom positioning case, the buoyant warm fluid is produced at the bottom region of the tank and during its rising, it causes a sever mixing inside the tank and hence, a large mixing region with a low quality warm water, which occupies more than the half of the tank volume, is formed. This region with a uniform low quality warm fluid is evident in Figs. $11 \mathrm{c}$ and $11 \mathrm{~d}$. For this case the temperature incursion is also evident especially during early warming periods and it progressively diminishes as time elapses. For the case of middle positioning, a better thermal stratification is developed in compare with the bottom positioning. For this case, the top uniform mixing layers formed have a higher temperature than the former case with a narrower thickness. At this case, although a favorable thermal stratification is developed during the time, however, the usable top hot water quality is still not good enough. For the case of top positioning, it is seen that the most favorable thermal stratification is developed inside the tank with thinner thermocline region which is an indication of least mixing inside the storage tank. The top of the tank is occupied with a high quality hot fluid while the bottom region is occupied with an almost motionless cold fluid.

The foregoing discussion indicates that the better tank performance may be achieved when the mantle heat exchanger is in its top position. However, this is true for early warming period and up to around $t=1000$. At longer charging periods, the middle mantle positioning case shows better performance as may be seen in Fig. 12 in which the centerline temperature profiles are shown for only top and middle positioning cases and for various nondimensional times. It is seen that the top layer temperatures are always higher with narrower thickness for top positioning case. Hence as time elapses, the temperature difference between the top layer fluids in the tank and mantle fluid stream becomes smaller and hence after certain amount of time, the heat transfer between the two fluids become negligible and the mantle fluid stream exits from the bottom of the mantle with almost its initial hot temperature without almost any transferring its energy to the tank fluid. Therefore, the mantle heat exchanger losses its performance accordingly. However, for the middle positioning case, the top layers become warmer and warmer as time elapses and the thickness of the top layers hot fluid is also increases as time progresses. Therefore, a superior performance is achieved for the middle positioning case, as in this case, a thicker hot layer fluid in the upper portion of the tank with a nondimensional temperature more than 0.9 is formed, indicating good extraction efficiency. Meanwhile, for the middle positioning case, higher amount of energy is recoverable from the tank as the top good quality hot layers have a higher thickness in comparison with the top positioning case.

\subsection{The influence of the mantle Reynolds number}

In this section, the influence of the mantle inlet mass flow rate or mantle inlet velocity on the transient thermal performance of the storage tank is investigated and the evolution of the thermal stratification inside the tank which is initially filled with uniform cold water is studied. The mantle inlet velocity is represented by its inlet Reynolds number and hence the tank thermal performance is investigated for three different mantle inlet velocity or inlet Reynolds number of 10, 20 and 40. For each case, the tank Rayleigh number is equal to $R a=1 . \times 10^{8}$ and the mantle heat exchanger is in the middle position around the storage tank.

In Fig. 13, the isotherms and streamlines inside the tank are shown for three selected Reynolds number and at the non-dimensional time of $t=1000$. It is seen that by increasing the mantle Reynolds number, the streamlines are not much differ from each other and all of them show almost the same flow pattern inside the tank. The top uniform mixing regions produced have a same thickness for three cases. However, it is seen from the isotherm patterns that this mixing region achieve a higher temperature as $R e$ is increased. This is again due to the higher heat transfer rate between the hot mantle stream and the fluid inside the storage tank for higher values of the mantle Reynolds number.

Moreover, by increasing inlet fluid velocity to the heat exchanger, a higher amount of thermal energy stored in the heat storage tank is achieved for a same period of time.

In Fig. 14, the vertical temperature profile along the centerline of the tank is displayed for various values of the 
mantle Reynolds number and for two values of the nondimensional time. A stable thermal stratification is developed during the time. At the same time period, a higher temperature levels over the entire region in the tank, especially at the top regions, are observed for higher values of the Reynolds number. However, the thickness of the top mixing layer fluid in the tank is marginally higher for the higher values of Reynolds number. The same temperature profile patterns are observed for higher values of nondimensional time.

\section{CONCLUSION}

The purpose of this investigation is to numerically study the transient thermal behavior of a vertical storage tank employed in a solar domestic heating water system with a mantle heat exchanger. Numerical simulation is based on a two dimensional mass, momentum and energy conservation equations as well as two additional turbulence variable equations in the cylindrical co-ordinates. Equations have been discretized in finite volume method. SIMPLER algorithm is used for coupling pressure and momentum equations. Transient thermal behavior of heat storage tank has been studied and presented in the form of streamlines and isotherm lines and temperature profiles in the symmetry axis of the heat storage tank in the axial direction. The effect of Rayleigh number, the position of heat exchanger around the heat storage tank and the mantle Reynolds number on thermal performance of the heat storage tank have been studied. The conclusions obtained from this work can be summarized as follow:

1. As the hot fluid flow is initiated through the mantle heat exchanger, the tank cold fluid adjacent to the interface of the heat exchanger and the tank is progressively heated and flows upward due to the buoyancy force, and simultaneously pushes the cold fluid to drop down around the centerline to the lower part of the tank. Such fluid movement makes the hot fluid take place over the cold fluid and as a result, thermal stratification is created in the heat storage tank.

2. Increasing Rayleigh number will increase buoyant uprising warm flow adjacent to the vertical wall and therefore, a more stable and favorable thermal stratification is formed inside the heat storage tank.

3. In the case of positioning the mantle heat exchanger in the upper section around the heat storage tank, thermal stratification is formed at the higher height inside the tank, also fluid temperature in the upper part of the tank is higher than the two other positioning cases. However, as time elapses, the middle positioning case shows superior thermal performance. For the middle positioning case, higher amount of energy is recoverable from the tank as the top good quality hot layers have a higher thickness in comparison with the top positioning case. Therefore, placing the peripheral mantle in the middle height is recommended.

4. Increasing the hot fluid velocity entered into the mantle heat exchanger will increase fluid momentum and inlet flow rate. This enhances the rate of heat transfer between fluid inside the heat exchanger and fluid inside the tank. At the same time period, a higher temperature levels over the entire region in the tank, especially at the top regions, are observed for higher values of the Reynolds number. Therefore, a higher amount of thermal energy stored in the heat storage tank is achieved for a same period of time and the tank is reached to its utilizing period at a closer time.

\section{REFERENCES}

Alizadeh, S. (1999). An experimental and numerical study of thermal stratification in a horizontal cylindrical solar storage tank. Solar Energy 66, 409-421.

Andres, A.C. and J.M.C. Lopez (2002). TRNSYS model of a thermosyphon solar domestic water heater with a horizontal store and mantle heat exchanger, Solar Energy 72, 89-98.

Barzegar, A. (2007). Numerical study of thermal performance of a vertical solar storage tank with mantle heat exchanger. M.Sc. Thesis, Yazd University.

Cheeswright, R., K.J. King, and S. Ziai (1986). Experimental data for the validation of computer codes for the prediction of tow-dimensional buoyant cavity flows. In: J.A.C. Humphrey, C.T. Avedisian, B.W.L. Tourneau, and M.M. Chen (Eds.), Significant questions in buoyancy affected enclosure or cavity flows, HTD60 ASME, 75-81.

Cole, R.L. and F.O. Bellinger (1982). Thermally stratified tanks, ASHRAE Transactions 88, 1005-1017.

Dehghan, A.A., M.H. Hosni, and S.H. Shiryazdi (2005). Experimental evaluation of the thermal behavior of a vertical solar tank using energy and exergy analysis. Proceeding of IMECE2005, Florida, USA.

Eames, P.C. and B. Norton (1998). The effect of tank geometry on thermally stratified sensible heat storage subject to low Reynolds number flow. Int. J. Heat Mass Transfer 41, 2131-2142.

Hahne, E. and Y. Chen (1998). Numerical study of flow and heat transfer characteristics in hot water stores, Solar Energy 64, 9-18.

Ismail, K.A.R., Leal, J.F.B., Zanardi, M.A. (1997). Models of Liquid Storage Tanks, Int. J. Energy Research 22, 805-815.

Lavan, Z. and Y. Thompson (1977). Experimental study of thermally stratified hot water storage tanks. Solar Energy 19, 519-524.

Lemember, A. and P. Petit (1998). Laminar natural convection in a laterally heated and upper cooled vertical cylindrical enclosure, Int. J. Heat Mass transfer 41, 2437-2454. 
A. Barzegar and A.A. Dehghan / JAFM, Vol. 2, No. 1, pp. 55-69, 2009.

Lightstone, M.F., G.D. Raithby, and K.G.T. Hollands (1989). Numerical simulation of the charging of liquid storage tanks: comparison with experiment, J. of Solar Energy Engineering 111, 225-231.

Miller, C.W. (1995). Effect of Conducting Wall on a Stratified Fluid in a Cylinder. AIAA Paper No.77-792, AIAA $12^{\text {th }}$ Thermophysics Conference, Albuquerque, New Mexico.

Morrison, G.L., G. Rosengarten, and M. Behnia (1999). Mantle heat exchanger for horizontal tank thermosyphon solar water heaters, Solar Energy 67, 53-64.

Nelson, J.E.B., A.R. Balakrishnan, and S.S. Murthy (1997). Parametric study on thermally stratified child water storage systems, Applied Thermal Engineering 19, 89115 .

Oliveski, R.C., A. Krenzinger, and H.A. Vielmo (2003). Cooling of cylindrical vertical tanks submitted to natural internal convection, Int. J. Heat Mass Transfer 46, 2015-2026.

Papanicolaou, E. and V. Belessiotis (2002). Transient natural convection in a cylindrical enclosure at high Rayleigh numbers, Int. J. Heat Mass Transfer 45, 1425-1444.

Patankar, S.V. (1980). Numerical Heat Transfer and Fluid Flow. McGraw-Hill, New York.

Peng, S.H. and L. Davidson (1999). Computation of turbulent buoyant flows in enclosures with lowReynolds-number k- $\omega$ models, Int. J. Heat Fluid Flow 20, 172-184.
Shariha, A.M. and G.O.G. Lof (1996). The optimization of tank volume to collector area ratio for thermosyphon solar water heater, Renewable Energy 7, 289-300.

Shyu, R.J., J.Y. Lin, and L.J. Fang (1989). Thermal analysis of stratified storage tanks. ASME J. Solar Energy Eng. 111, 54-61.

Versteegh, H.K. and W. Malalasekera (1995). An Introduction to Computational Fluid Dynamics: The Finite Volume Method. Harlow, England, Longman Scientific\& Technical.

Wilcox, D.C. (1993). Turbulence Modeling for CFD. DCW Industries, Inc., La Canada, California.

Wildin, M.W. (1996). Experimental results from singlepipe diffusers for stratified thermal energy storage, ASHRAE Transactions 102 (2), 123-132.

Wildin, M.W. and C.R. Truman (1985). A Summery of experience with stratified child water tanks, ASHRAE Transactions 92, 956-976.

Zurigat, Y.H. (1989). A comparison study of onedimensional models for stratified thermal storage tanks. ASME J. Solar Energy Eng. 111, 205-210.

Zurigat, Y.H., A.H. Ghajar, and P.M. Moretti (1988). Stratified thermal energy storage tank inlet mixing characterization, Applied Energy 30, 99-111. 
A. Barzegar and A.A. Dehghan / JAFM, Vol. 2, No. 1, pp. 55-69, 2009.

Table 1 The coefficients of the generalized governing equations and their turbulence parameters

\begin{tabular}{|c|c|c|c|c|}
\hline \multirow{2}{*}{$\begin{array}{l}\text { Governing } \\
\text { equations }\end{array}$} & \multicolumn{2}{|c|}{$\Gamma_{\phi}$} & \multirow{2}{*}{\multicolumn{2}{|c|}{$S_{\phi}$}} \\
\hline & Natural convection & Forced convection & & \\
\hline Continuity & 0 & 0 & \multicolumn{2}{|l|}{0} \\
\hline $\begin{array}{l}\text { Momentum } \\
\text { equation in } r \\
\text { direction }\end{array}$ & $\frac{1}{G r^{\frac{1}{2}}}\left(1+v_{t}^{*}\right)$ & $\frac{1}{\operatorname{Re}}\left(1+v_{t}^{*}\right)$ & $-\frac{\partial P}{\partial r}+\Gamma_{\phi}^{\prime}\left[\begin{array}{l}\frac{\partial}{\partial z}\left(\left(1+v_{t}^{*}\right) \frac{\partial u_{z}}{\partial z}\right)+ \\
\frac{1}{r} \frac{\partial}{\partial r}\left(r\left(1+v_{t}^{*}\right) \frac{\partial u_{r}}{\partial r}\right. \\
2\left(1+v_{t}^{*}\right) \frac{u_{r}}{r^{2}}\end{array}\right.$ & \\
\hline $\begin{array}{l}\text { Momentum } \\
\text { equation in } z \\
\text { direction }\end{array}$ & $\frac{1}{G r^{\frac{1}{2}}}\left(1+v_{t}^{*}\right)$ & $\frac{1}{\operatorname{Re}}\left(1+v_{t}^{*}\right)$ & $-\frac{\partial P}{\partial z}+\Gamma_{\phi}^{\prime}\left[\begin{array}{l}\frac{\partial}{\partial z}\left(\left(1+v_{t}^{*}\right) \frac{\partial u_{z}}{\partial z}\right)+ \\
\frac{1}{r} \frac{\partial}{\partial r}\left(r\left(1+v_{t}^{*}\right) \frac{\partial u_{r}}{\partial z}\right.\end{array}\right]+$ & $+\Gamma_{v} T$ \\
\hline $\begin{array}{l}\text { Turbulence } \\
\text { kinetic energy }\end{array}$ & $\frac{1}{G r^{\frac{1}{2}}}\left(1+\frac{v_{t}^{*}}{\sigma_{k}}\right)$ & $\frac{1}{\operatorname{Re}}\left(1+\frac{v_{t}^{*}}{\sigma_{k}}\right)$ & $\Gamma_{\phi}^{\prime}\left(P_{k}+S_{k}\right)-\pi_{k}$ & \\
\hline $\begin{array}{l}\text { The second } \\
\text { turbulence } \\
\text { equation }\end{array}$ & $\frac{1}{G r^{\frac{1}{2}}}\left(1+\frac{v_{t}^{*}}{\sigma_{z}}\right)$ & $\frac{1}{\operatorname{Re}}\left(1+\frac{v_{t}^{*}}{\sigma_{z}}\right)$ & \multicolumn{2}{|l|}{$\Gamma_{\phi}^{\prime}\left(P_{Z}+S_{Z}\right)-\pi_{Z}$} \\
\hline Energy & $\frac{1}{G r^{\frac{1}{2}}}\left(\frac{1}{\operatorname{Pr}}+\frac{v_{t}^{*}}{\operatorname{Pr}_{t}}\right)$ & $\frac{1}{\operatorname{Re}}\left(\frac{1}{\operatorname{Pr}}+\frac{v_{t}^{*}}{\operatorname{Pr}_{t}}\right)$ & 0 & \\
\hline \multicolumn{5}{|c|}{ In natural convection $\Gamma_{\phi}^{\prime}=\frac{1}{G r^{1 / 2}}$ and in forced convection $\Gamma_{\phi}^{\prime}=\frac{1}{\mathrm{Re}}$. } \\
\hline \multicolumn{4}{|c|}{$f_{1}=\frac{0.1+R_{t} / 2.7}{1+R_{t} / 2.7} f_{\mu}^{-1}, \quad f_{k}=\frac{0.278+\left(\left(R_{t} / 8\right)^{4}\right.}{1+\left(R_{t} / 8\right)^{4}}, \quad f_{\mu}=\frac{0.025+R_{t} / 6}{1+R_{t} / 6}, \quad R_{t}=\frac{k^{2}}{\omega v}$} & \\
\hline \multicolumn{5}{|c|}{$c_{1}=0.56, c_{2}=0.075, c_{k}=0.09, c_{\mu}=1.0, \sigma_{k}=2.0, \sigma_{z}=2.0, \sigma_{T}=0.9$} \\
\hline
\end{tabular}


A. Barzegar and A.A. Dehghan / JAFM, Vol. 2, No. 1, pp. 55-69, 2009.

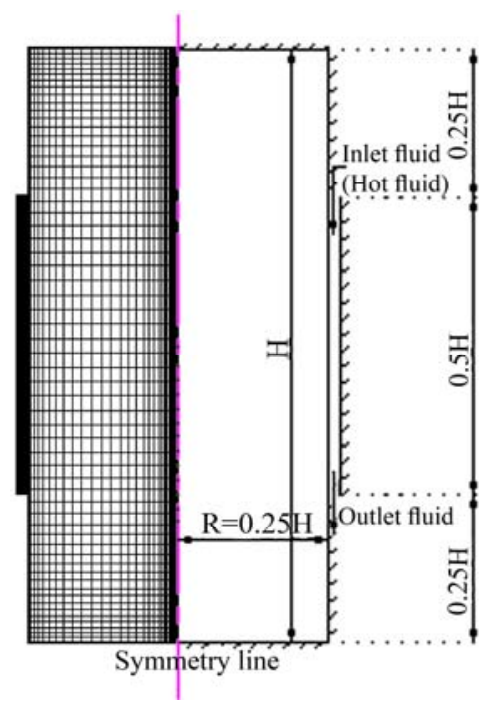

Fig. 1. The schematic diagram of the vertical storage tank under study with mantle heat exchanger

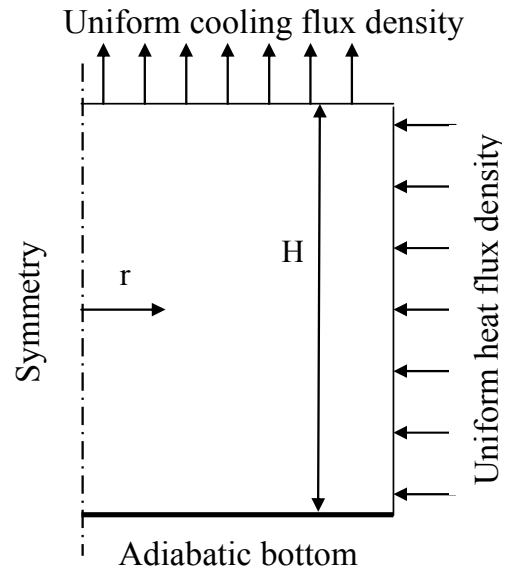

Fig. 2. The schematic of the geometry used by Lemember and Petit (1998)

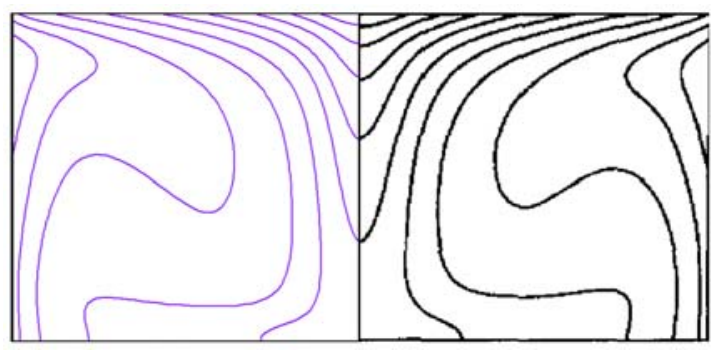

Fig. 3. Comparison of obtained temperature contours (left) with Lemember and Petit (1998) (right). $\frac{H}{D}=\frac{1}{2}, \operatorname{Pr}=0.7, R a=1.0 \times 10^{5}$ 
A. Barzegar and A.A. Dehghan / JAFM, Vol. 2, No. 1, pp. 55-69, 2009.

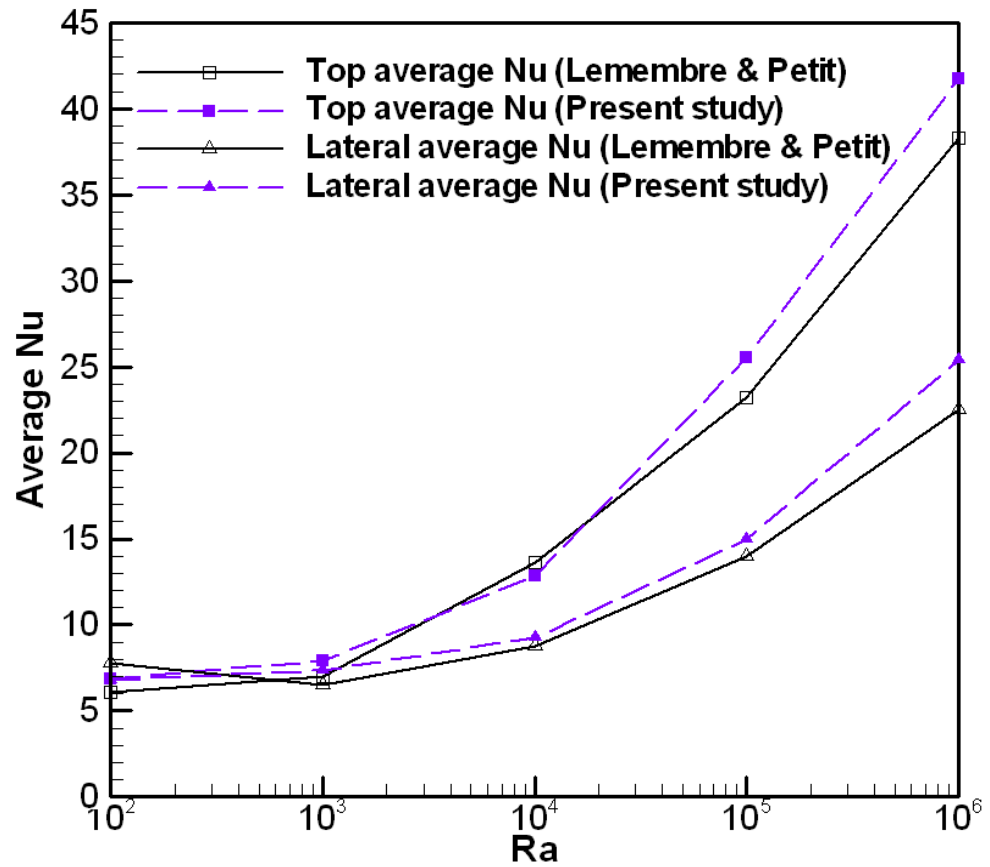

Fig. 4. Comparison of average Nusselt number versa Rayleigh number with Lemember and Petit (1998)

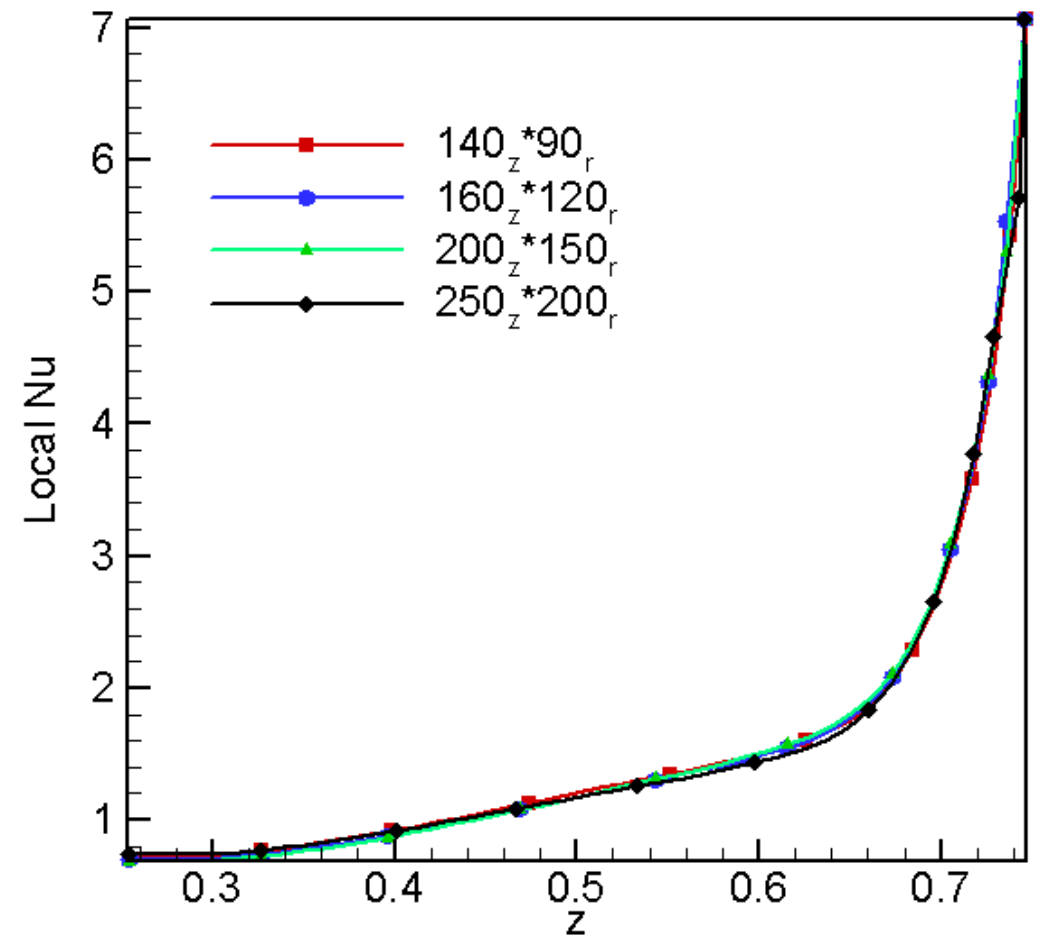

Fig. 5. The variation of Nusselt number along the tank and the mantle interface for different mesh sizes. 
A. Barzegar and A.A. Dehghan / JAFM, Vol. 2, No. 1, pp. 55-69, 2009.
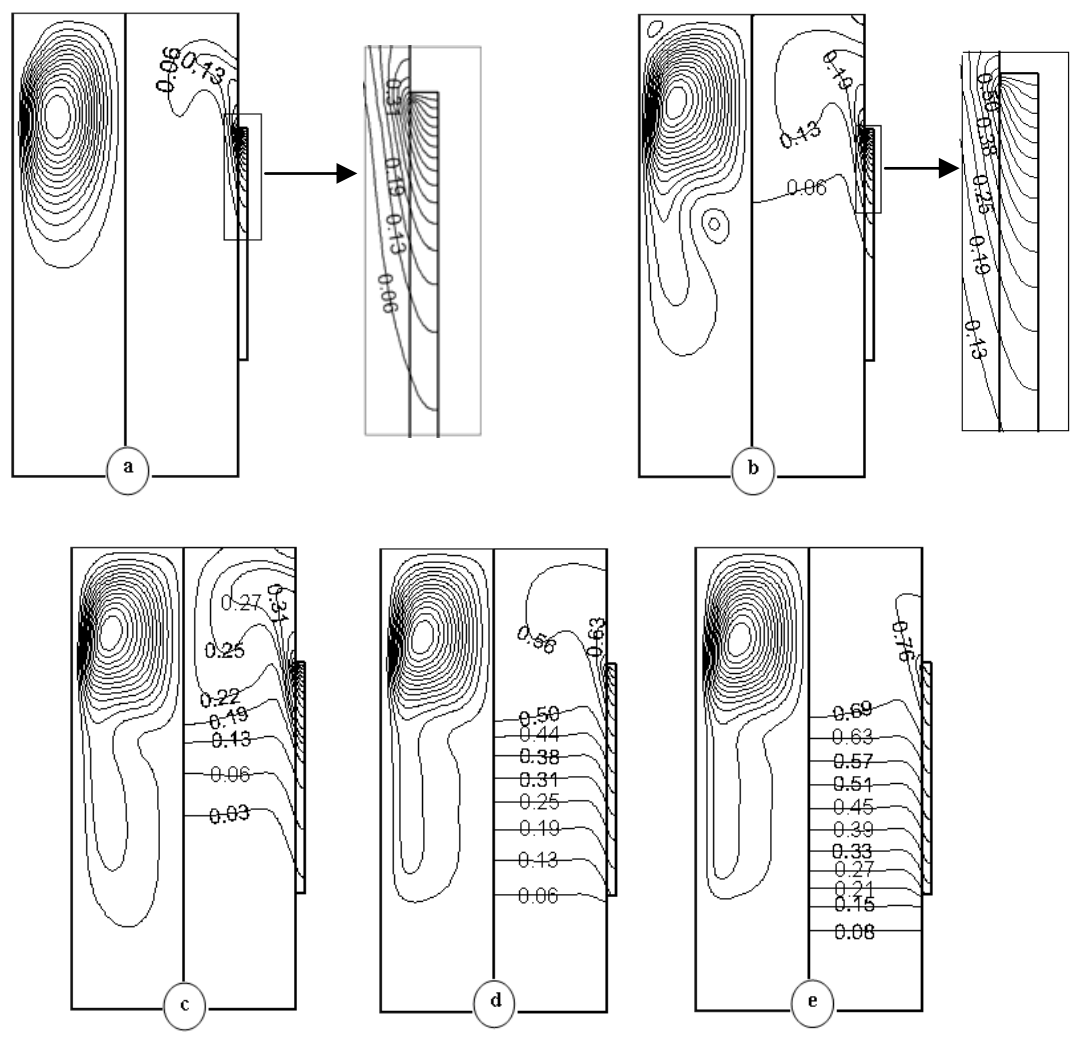

Fig. 6. Isotherm contours (right) and streamline contours (left) for $R a=1.0 \times 10^{7}$ a) $t=20$ b) $t=50$ c) $t=100$ d) $t=300$ e) $t=500$

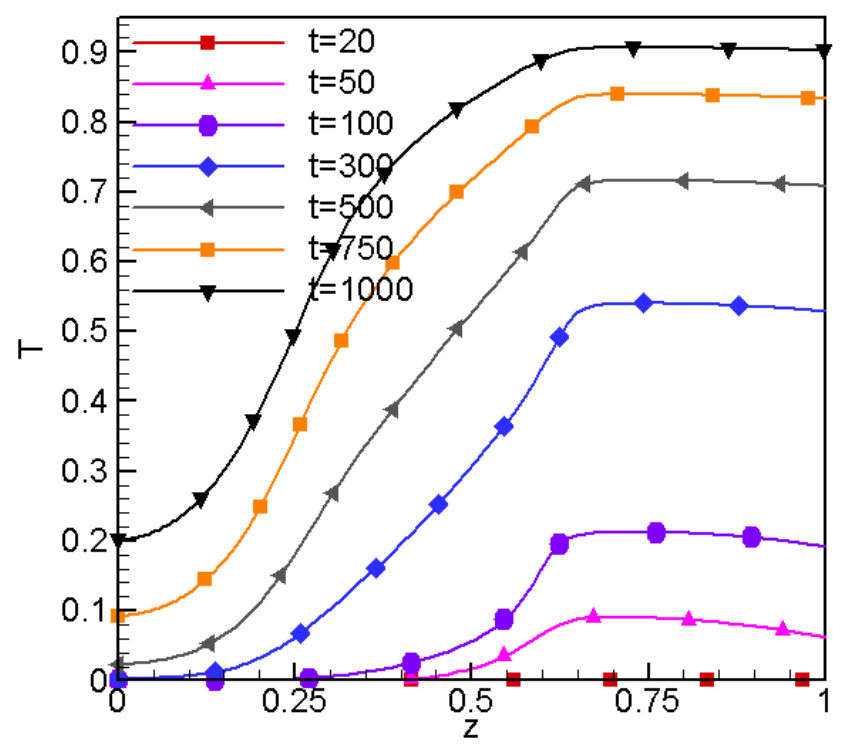

Fig. 7. Vertical temperature profile at centerline of the tank for $R a=1.0 \times 10^{7}$ 

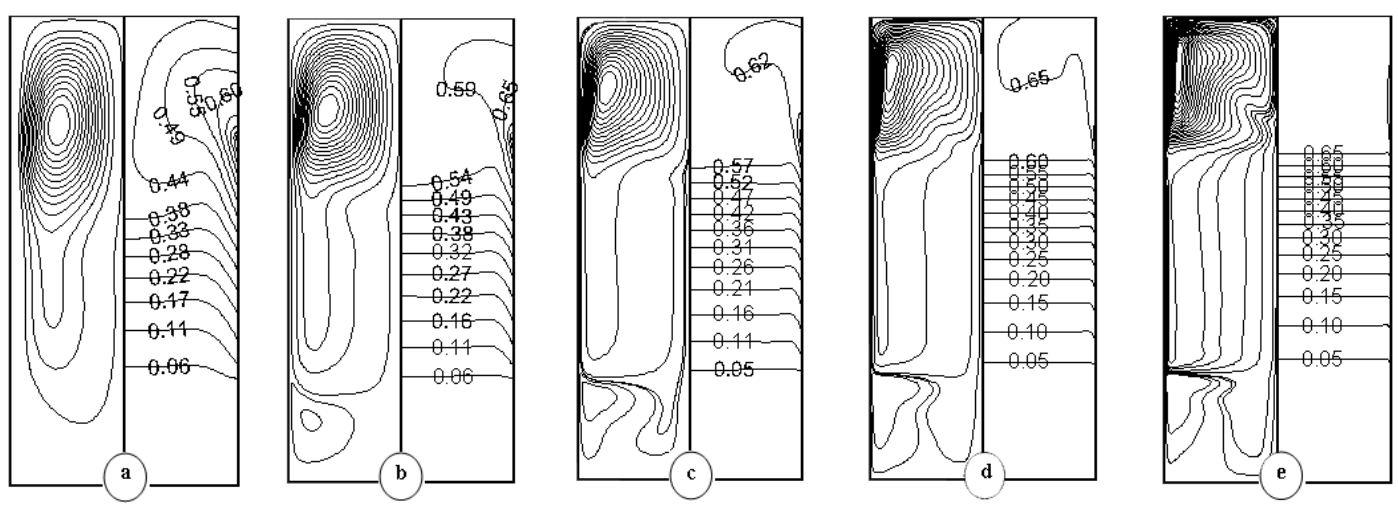

Fig. 8. Isotherm contours (right) and stream line contours (left) for normalized time of $\mathrm{t}=100$ a) $R a=1.0 \times 10^{6}$, b) $R a=1.0 \times 10^{7}$, c) $R a=1.0 \times 10^{8}$, d) $R a=1.0 \times 10^{9}$, e) $R a=1.0 \times 10^{10}$

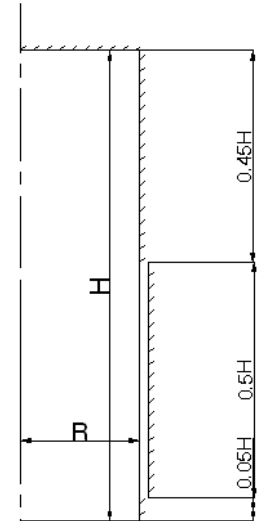

(a)

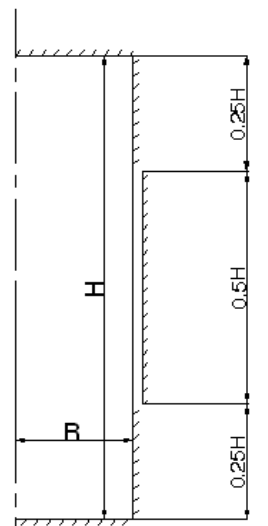

(b)

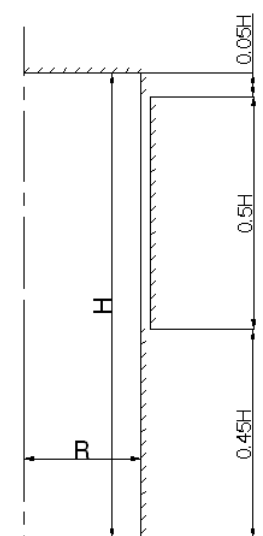

c

Fig. 9. Three different mantle heat exchanger positioning cases a) bottom positioning, b) middle positioning c) top positioning
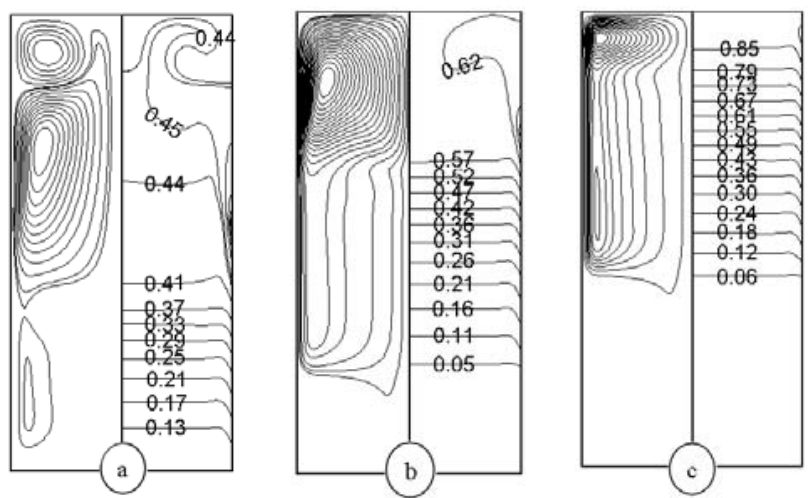

Fig. 10. Isotherm contours (right) and streamline contours (left) for different mantel positioning cases and for $R a=1.0 \times 10^{8}, \mathrm{t}=1000$

a)bottom positioning, b) middle positioning, c) top positioning 
A. Barzegar and A.A. Dehghan / JAFM, Vol. 2, No. 1, pp. 55-69, 2009.
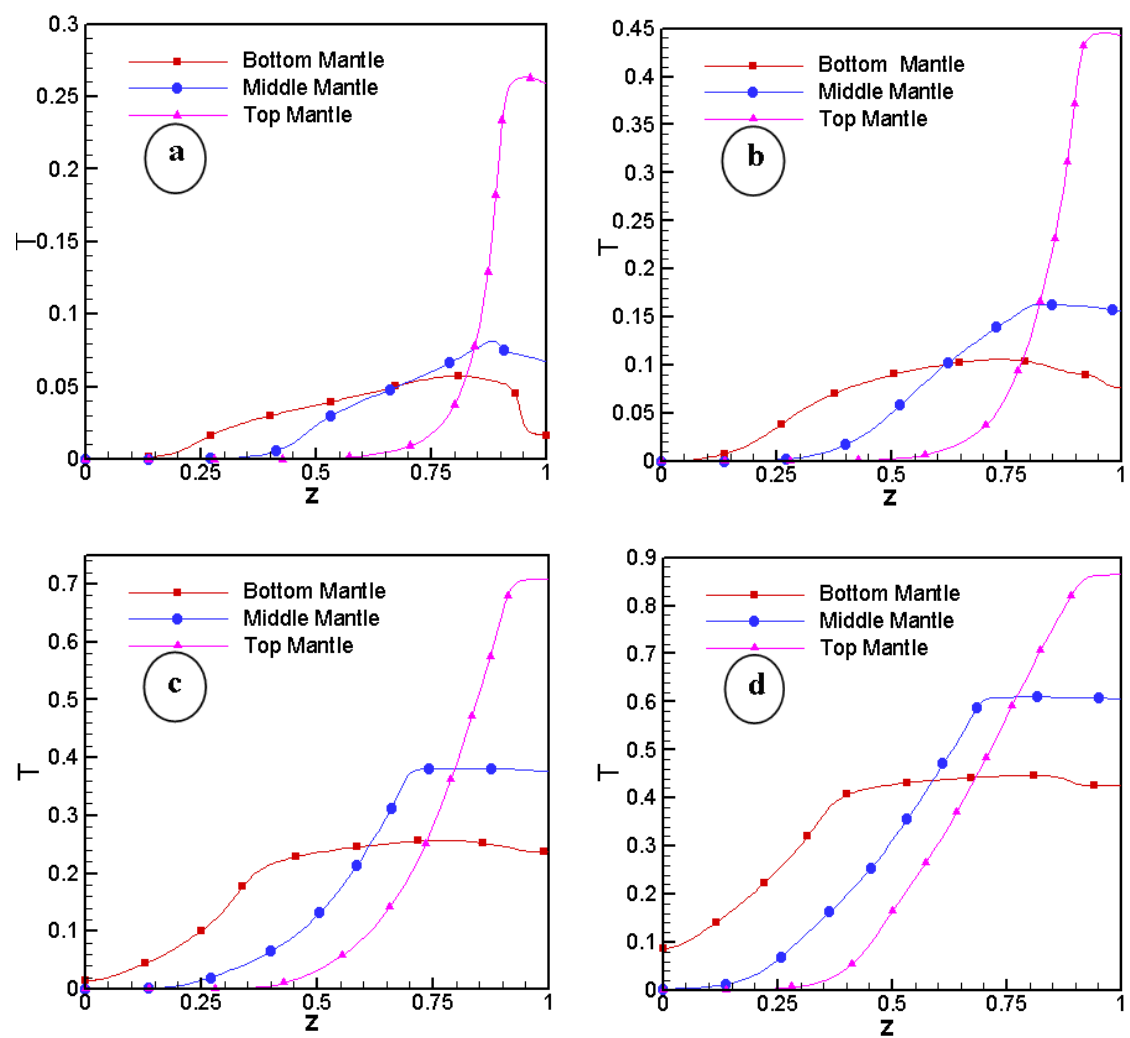

Fig. 11. Temperature profile at the centerline of the tank for three cases of the mantle heat exchanger positioning and for $\left.\left.\left.\left.R a=1.0 \times 10^{8} a\right) t=100, b\right) t=200, c\right) t=500, d\right) t=1000$
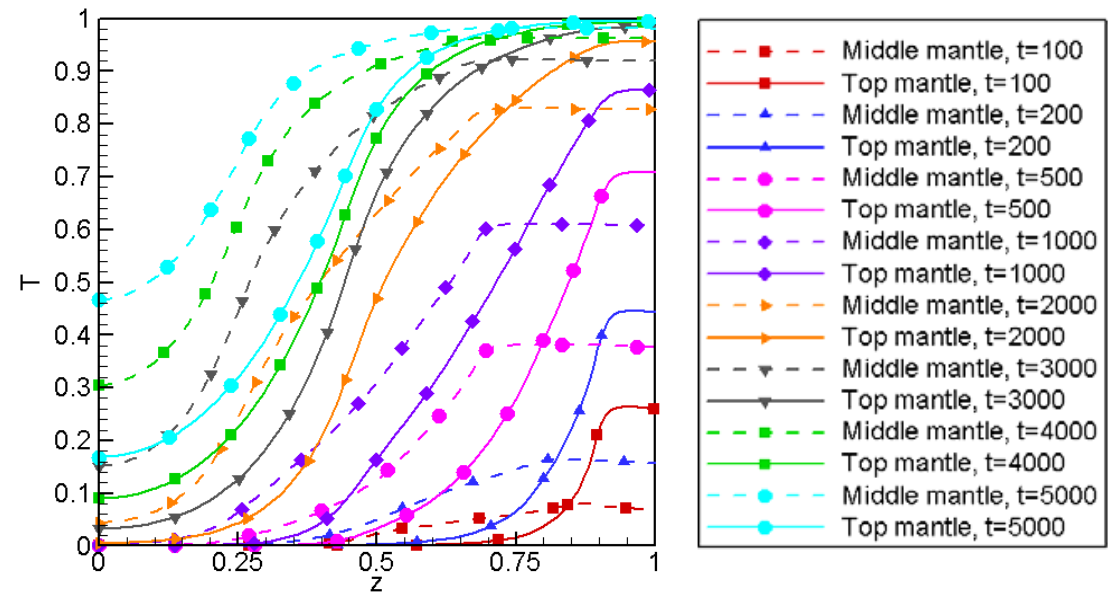

Fig. 12. Centerline temperature profiles for top and middle positioning cases and for various non-dimensional times 

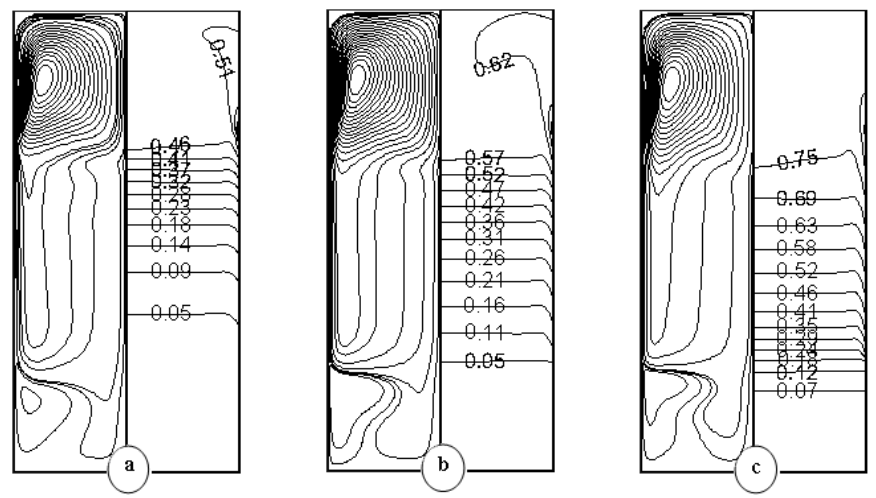

Fig. 13. Isotherm contours (right) and streamline contours (left) for $R a=1.0 \times 10^{8}, \mathrm{t}=1000$ a) $\left.\left.\mathrm{Re}=10, \mathrm{~b}\right) \mathrm{Re}=20, \mathrm{c}\right) \mathrm{Re}=40$
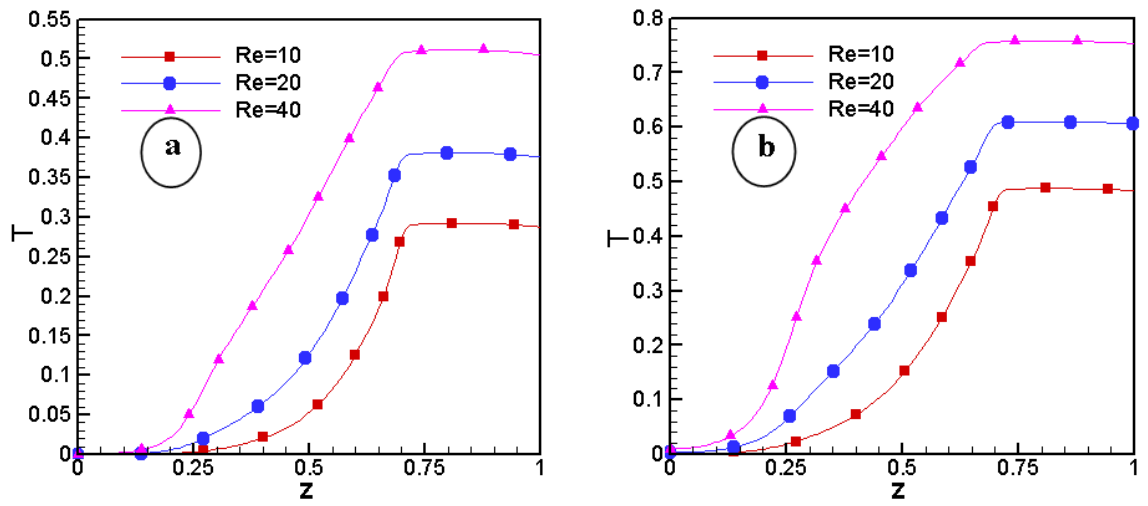

Fig. 14. Temperature profile at centerline of the tank for various mantle's Reynolds number and for $R a=1.0 \times 10^{8}$ a) $\left.\mathrm{t}=500, \mathrm{~b}\right) \mathrm{t}=1000$ 